\title{
Bahaya dan Dampak Penyalahgunaan Napza di Kalangan Pelajar
}

\author{
Rabiah Al Adawiah*1, Esther Masri ${ }^{2}$ \\ ${ }^{1,2}$ Fakultas Hukum, Universitas Bhayangkara Jakarta Raya, Indonesia \\ Jl. Raya Perjuangan Bekasi Utara, Kota Bekasi, Jawa Barat \\ *e-mail: rabiah.adawiah@dsn.ubharajaya.ac.id \\ *Phone : 081285761551
}

Informasi Artikel

Diterima Redaksi: 8 Desember 2021

Revisi Akhir: 20 Desember 2021

Diterbitkan Online: 15 Januari 2022

Kata Kunci:

Bahaya Napza, Pelajar, Penyalahgunaan Napza

\begin{abstract}
Abstrak
Angka penyalahgunaan NAPZA/Narkotika di Indonesia mencapai 3.419 .188 orang, dan $27 \%$ pengguna NAPZA tersebut dari kalangan pelajar. Besarnya angka ini menjadi masalah serius terutama bagi generasi muda. Penyalahgunaan NAPZA dapat membahayakan dan memberikan dampak yang serius terhadap fisik, psikis, bahkan dampak sosial bagi penggunanya. Dengan demikian menjadi sangat penting bagi semua pihak baik sekolah maupun orang tua untuk terus memberikan pengarahan yang baik mengenai bahaya penyalahgunaan NAPZA/Narkotika bagi masa depan pelajar.

Secara umum, tujuan dari kegiatan pengabdian kepada masyarakat berupa penyuluhan hukum penyalahgunaan Napza ini, yaitu: 1) Pihak sekolah turut mencegah terjadinya penyalahgunaan Napza di kalangan pelajar; 2) Kalangan pelajar dapat mengerti dan memahami bahaya dan dampak penyalahgunaan Napza dan aspek hukumnya. Metode kegiatan dilaksanakan dalam bentuk webinar melalui platform/aplikasi zoom antara narasumber dengan para peserta pelajar.
\end{abstract}

Beragam jenis NAPZA umumnya bekerja dengan meningkatkan ketersediaan dopamin di otak (suatu jenis neurotransmiter yang bekerja mengontrol rasa senang), sehingga mengaktifkan sistem yang mengatur rasa senang di otak (reward system). Penggunaan NAPZA terus menerus akan membuat keberadaan dopamin beradaptasi dan semakin tinggi. Kondisi ini akan membuat pengguna NAPZA akan terus menjaga agar fungsi dopamin selalu ada dan terus berusaha meningkatkan dosis NAPZA untuk mencapai dopamin yang tinggi sehingga akan membuat pengguna NAPZA ketagihan atau kecanduan (Ikawati dalam Nur'artavia, 2017).

Narkotika adalah zat yang bila dipergunakan akan membawa efek dan pengaruh tertentu pada tubuh pemakai, yaitu mempengaruhi kesadaran terhadap sikap dan perilaku manusia. Pengaruh tersebut dapat berupa penenang, perangsang (bukan rangsangan seks), dan menimbulkan halusinasi. Soedjono dalam patologi sosial 
mendefenisikan Narkotika sebagai bahan atau zat yang mempunyai efek kerja pembiusan atau dapat menurunkan kesadaran (Soedjono, 2000). Sementara Badan Narkotika Nasional (BNN) memberi defenisi Narkotika sebagai zat atau obat baik yang bersifat alamiah, sintetis, maupun semi sintetis yang menimbulkan efek penurunan kesadaran, halusinasi, serta daya rangsang (BNN, 2019).

UU No 35 Tahun 2009 tentang Narkotika Pasal 1 Ayat 1 menyebutkan bahwa Narkotika adalah zat atau obat yang berasal dari tanaman atau bukan tanaman baik sintetis maupun semi sintetis yang dapat menyebabkan penurunan atau perubahan kesadaran, hilangnya rasa, mengurangi sampai menghilangkan rasa nyeri dan dapat menimbulkan ketergantungan yang dibedakan dalam beberapa golongan (UU Narkotika, 2009).

Dalam Undang-Undang No. 35 Tahun 2009 tentang Narkotika dijelaskan ada tiga jenis golongan narkotika, yaitu:

Narkotika Golongan I adalah Narkotika hanya dapat digunakan untuk tujuan pengembangan ilmu pengetahuan dan tidak digunakan dalam terapi serta mempunyai potensi sangat tinggi mengakibatkan ketergantungan. Contoh: Heroin, Kokain, Daun Koka, Opium, Ganja, Jicing, Katinon, Metilendioksimetamfetamina (MDMA)/Ecs tasy, dan lebih dari 65 macam jenis lainnya.

Narkotika Golongan II adalah Narkotika yang berkhasiat untuk pengobatan, digunakan sebagai pilihan terakhir dan dapat digunakan dalam terapi dan/atau untuk tujuan pengembangan ilmu pengetahuan serta mempunyai potensi tinggi mengakibatkan ketergantungan. Contoh: Morfin, Petidin, Fentanil, Metadon dan lainlain.

Narkotika golongan III adalah Narkotika yang memiliki daya adiktif ringan, tetapi bermanfaat dan berkhasiat untuk pengobatan dan penelitian. Golongan ke 3 ini banyak digunakan dalam terapi dan/atau untuk tujuan pengembangan ilmu pengetahuan serta mempunyai potensi mengakibatkan ketergantungan. Contoh: Codein, Buprenorfin, Etilmorfina, Kodeina, Nikokodina, Polkodina, Propiram, dan ada 13 (tiga belas) macam termasuk beberapa campuran lainnya. Untuk informasi lebih mendalam tentang jenis Narkotika dalam ketiga golongan tersebut dapat dilihat di lampiran Undang-undang Narkotika Nomor 35 Tahun 2009.

Adapun Psikotropika adalah zat atau obat, baik alamiah maupun sintetis bukan Narkotika yang berkhasiat psikoaktif melalui pengaruh selektif susunan saraf maupun pusat yang menyebabkan perubahan khas pada aktivitas mental dan perilaku, digunakan untuk mengobati gangguan jiwa, seperti depresi, gangguan kecemasan, gangguan bipolar, gangguan tidur, dan skizofrenia (Pane, 2021).

Zat Adiktif adalah zat atau bahan yang bukan berupa Narkotika dan psikotropika yang berpengaruh pada kerja otak. Tidak tercantum dalam peraturan perundang undangan tentang Narkotika dan psikotropika. Zat adiktif yang sering disalahgunakan diantaranya, Alkohol (merupakan nama yang dipakai untuk menamai senyawa organik yang terdiri dari unsur-unsur karbon, hydrogen dan oksigen dengan kombinasi dan kandungan yang berbeda), Inhalasi (merupakan gas atau zat yang mudah menguap yang biasanya terdapat pada berbagai keperluan pabrik dan rumah tangga namun disalahgunakan karena di dalamnya terdapat kandungan hallucinogen seperti zat lysergic acid diethylamide (LSD) pada lem aibon, aceton, eter, premix, thiner dan lain-lain (Ummu, 2008).

Di lingkungan medis, NAPZA sangat bermanfaat bagi kesembuhan dan keselamatan manusia, penggunaannya dibawah pengawasan dan tanggung jawab dokter dan apoteker dan diatur secara legal dengan ketentuan perundang-undangan. Hal ini dikarenakan NAPZA dapat disalahgunakan dan justru sangat membahayakan kondisi tubuh maupun psikis bagi orang yang memakainya. Namun, dewasa ini banyak yang telah menyalahgunakan NAPZA, penggunaannya bukan lagi untuk tujuan pengobatan melainkan untuk bersenang senang, dosis yang digunakan dalam jumlah yang berlebih, tidak teratur serta berlangsung cukup lama, sehingga menyebabkan gangguan kesehatan fisik, mental, gangguan perilaku dan kehidupan sosial (Martono \& Joewana, 2006).

Penyalahgunaan NAPZA sudah marak terjadi. Perserikatan Bangsa-Bangsa urusan 
Obat-obatan dan Kejahatan atau UNODC (United Nations Office on Drugs and Crime) mengemukakan pada tahun 2020 sebanyak 275 juta orang di seluruh dunia termasuk Indonesia menyalahgunakan NAPZA/Narkotika. Berdasarkan survei yang dilakukan oleh Badan Narkotika Nasional (BNN) bekerjasama dengan Lembaga Ilmu Pengetahuan Indonesia (LIPI) menyebutkan angka penyalahgunaan NAPZA/Narkotika di Indonesia mencapai 3.419.188 orang (Republika, 2021), dan $27 \%$ pengguna NAPZA di Indonesia dari kalangan pelajar (Beritasatu, 2021). Angka ini cukup besar dan menjadi masalah serius terutama bagi generasi muda.

Kalangan pelajar merupakan kelompok usia remaja yang mudah terpengaruh untuk menyalahgunakan NAPZA, karena usia remaja masih memiliki emosi dan mental yang labil, rasa ingin tahu yang besar, mudah meniru atau mencontoh (ikut-ikutan), dan rasa solidaritas kelompok yang kuat. Rasa ingin tahu terhadap NAPZA menjadi salah satu pendorong bagi seseorang untuk melakukan perbuatan yang menyimpang termasuk rasa ingin tahu terhadap NAPZA.

Menurut Willis, penyalahgunaan NAPZA di kalangan pelajar dapat diilustrasikan dalam skala besar, bahwa pelajar yang sering bergaul di luar rumah akan mudah untuk menyalahgunakan NAPZA karena mudah terpengaruh serta teman-teman penyalahguna maupun pengedar NAPZA sangat mahir untuk membujuknya. Pelajar yang sudah memiliki ketergantungan atau kecanduan menjadi pengedar, selanjutnya dapat mempengaruhi teman-teman lainnya, hingga satu sekolah menjadi tempat peredaran NAPZA. Pelajar penyalahguna NAPZA bisa saja dikeluarkan dari sekolah supaya siswa lainnya tidak terkena pengaruh buruknya. Lalu pelajar tersebut kesulitan untuk mencari sekolah yang baru dan menjadi siswa putus sekolah. Kemungkinan selanjutnya pelajar putus sekolah tersebut semakin leluasa bergaul dengan teman-teman pengguna NAPZA lainya, dan berakibat ditangkap oleh polisi dan masuk penjara (Willis, 2014).

Penyalahgunaan NAPZA dapat membahayakan dan memberikan dampak yang serius di kalangan pelajar. NAPZA membuat pemakainya kecanduan dan ketergantungan, semakin lama mengonsumsinya, maka akan semakin kuat memakai zat tersebut dan dosisnya pun meningkat secara eskalatif. Jika tidak mengkonsumsi zat itu, maka akan tersiksa dan berdampak pada tindakan yang akan melakukan segala cara demi mendapatkan NAPZA, bahkan dapat melakukan tindakan kriminal. Penyalahgunaan NAPZA memberikan dampak terhadap fisik, psikis, bahkan dampak sosial bagi penggunanya.

Dampak Fisik yang dapat ditimbulkan dari penyalahgunaan NAPZA yaitu; gangguan pada syaraf, jantung dan pembuluh darah, gangguan pada kulit, gangguan pada paru-paru, sering sakit kepala, mual dan mutah, serta berdampak pada reproduksi remaja perempuan antara lain perubahan menstruasi. Jika menggunakan NAPZA/Narkotika terlalu banyak, maka akan menimbulkan hal yang fatal seperti kematian (BNN, 2020).

Adapun dampak Psikis dari penyalahgunaan NAPZA yaitu dapat menimbulkan gangguan psikis, keracunan obat dan gejala putus obat pada pemakai narkotika akan menimbulkan rasa gelisah, takut, curiga yang berlebihan, lambat dan ceroboh kerja, sering tegang, hilang kepercayaan diri, penghayal, fobia, menjadi ganas dan brutal, perasaan tertekan dan cenderung menyakiti diri sendiri (Irwansyah, 2006).

Sedangkan dampak Sosial dari penyalahgunaan NAPZA berupa gangguan mental, dikucilkan di lingkungan, merepotkan dan menjadi beban keluarga, anti sosial, pendidikan menjadi terganggu dan masa depan suram. Dampak fisik, psikis dan sosial ini saling terkait, fisik akan membuat rasa sakit yang luar biasa bila terjadi putus obat, maka keinginan (psikis) yang muncul sangat kuat untuk mengonsumsi zat tersebut. Gejala ini berkaitan erat dengan gejala sosial seperti membohongi orang tua, mencuri, pemarah, bahkan menipu seseorang untuk mendapatkan NAPZA (Assiediqie, 2019).

Bagi pelajar yang menyalahgunakan NAPZA juga berdampak pada pendidikannya, terutama penurunan prestasi di sekolah. Banyak kasus pelajar penyalahguna NAPZA jadi putus sekolah. Pelajar yang menyalahgunakan NAPZA akan kehilangan keinginan dan semangat belajar, sering membolos, tidak 
mempedulikan kesehatan diri, mudah marah, memicu pertengkaran hingga tawuran, bahkan rela mencuri agar dapat membeli NAPZA (Marpaung, 2019).

Dengan kondisi yang telah dijabarkan di atas, maka perlu untuk terus melakukan sosialisasi terutama di kalangan pelajar mengenai bahaya dan dampak yang ditimbulkan dari penyalahgunaan NAPZA. Hasil penelitian yang telah dilakukan oleh Firdaus dan Hidayati menunjukkan bahwa pengetahuan tentang NAPZA dan penyalahgunaannya akan mengarahkan remaja agar tidak pernah menggunakan bahkan mencoba zat berbahaya tersebut, serta bersikap menolak ajakan teman maupun pengaruh lingkungan untuk menggunakannya (Firdaus \& Hidayati, 2018)

Selama ini, banyak kegiatan penyuluhan NAPZA yang telah dilakukan guna menyadarkan kalangan pelajar, namun bukan berarti kegiatan itu sudah cukup, melainkan harus terus dilakukan mengingat kalangan pelajar terus tumbuh dan berganti, serta demi menjaga agar generasi masa depan bangsa terhindar dari penyalahgunaan NAPZA. Dengan demikian menjadi sangat penting bagi semua pihak baik sekolah maupun orang tua untuk terus memberikan pengarahan yang baik mengenai bahaya penyalahgunaan NAPZA bagi masa depan pelajar.

\section{METODE}

Kegiatan penyuluhan dilaksanakan pada hari Kamis, 25 November 2021 dalam bentuk ceramah dan tanya jawab melalui platform/aplikasi zoom antara narasumber dengan para siswa SMAN 9Bekasi. Penyuluhan terdiri dari 3 (tiga) sesi, yaitu: pertama, penyuluhan materi tentang pengertian, jenis, bahaya, dampak serta pencegahan penyalahgunaan NAPZA / Narkotika. Kedua, pemberian materi tentang aspek dan dampak hukum terkait penyalahgunaan NAPZA/Narkotika. Ketiga, sesi tanya-jawab, yaitu setelah pemaparan oleh 2 (dua) pemateri selanjutnya dibuka tanya-jawab antara peserta kegiatan dengan pemateri. Pelaksanaan penyuluhan hukum ini dipandu oleh moderator dengan memberikan penjelasan mengenai topik kegiatan sebelum sesi kegiatan dimulai.

\section{HASIL DAN PEMBAHASAN}

Kegiatan penyuluhan ini diikuti oleh siswa siswi SMAN 9 Bekasi dan dilaksanakan pada hari Kamis, 25 November 2021. Penyuluhan dilaksanakan selama 2 jam (120 menit). Adapun hasil yang dicapai dari pengabdian kepada masyarakat melalui penyuluhan hukum tentang bahaya dan dampak penyalahgunaan NAPZA di kalangan pelajar, yaitu:

Pertama, peserta antusias mengikuti kegiatan yang ditandai dengan ikut sertanya mereka meskipun hari libur karena bertepatan dengan hari guru nasional, kuota terbatas dan hanya melalui aplikasi zoom. Para peserta siswa siswi SMAN 9 Bekasi ingin mengetahui lebih dalam terkait pengertian NAPZA, jenis dan golongannya, serta efek dari penggunaan NAPZA. Penggunaan NAPZA mempunyai efek Jangka Pendek antara lain; Gangguan terhadap daya ingat, Hipertermia, Tremor, Insomnia, dan meningkatnya Denyut jantung. Efek Jangka Panjang dari pemakaian NAPZA diantaranya; Penurunan kinerja otak, Gangguan mental, Perilaku agresif atau kekerasan, dan Kerusakan gigi yang parah (Swari, 2021). Selama webinar penyuluhan hukum berlangsung, para siswa siswi fokus terhadap materi yang dipaparkan oleh dua pemateri.

Kedua, peserta aktif dalam sesi tanyajawab, hal ini menandakan rasa ingin tahu mereka yang besar mengenai dampak secara fisik, psikis, dan sosial dari penyalahgunaan NAPZA, dimana dampak fisik jika menggunakan NAPZA antara lain; Gangguan pada sistem syaraf (neurologis) seperti: kejang-kejang, halusinasi, gangguan kesadaran, kerusakan syaraf tepi, Gangguan pada kulit (dermatologis) seperti: penanahan (abses), alergi, eksim, dan Dampak terhadap kesehatan reproduksi yaitu gangguan pada endokrin, seperti: penurunan fungsi hormon reproduksi (estrogen, progesteron, testosteron), serta gangguan fungsi seksual (BNN, 2020).

Ketiga, peserta penyuluhan mengerti akibat hukum dari penyalahgunaan NAPZA dan sanksinya yang diatur dalam UU. Konsekuensi hukum yang akan diterima oleh seseorang yang menyalahgunakan NAPZA tercantum dalam Pasal 111, Ayat 1 dan 2, Pasal 112 Ayat 1 dan 2, Pasal 113, Pasal 114 Ayat 1 dan 2, Pasal 127 Ayat 1,2, 
dan 3, serta Pasal 54 terkait rehabilitasi medis dan sosial bagi pengguna yang telah menjadi korban atau pecandu NAPZA (UU Nomor 35 Tahun 2009 tentang Narkotika).

Berikut dokumentasi kegiatan sebelum dan saat pelaksanaan webinar penyuluhan hukum tentang Bahaya Dan Dampak Penyalahgunaan Napza Di Kalangan Pelajar SMAN 9 Bekasi:

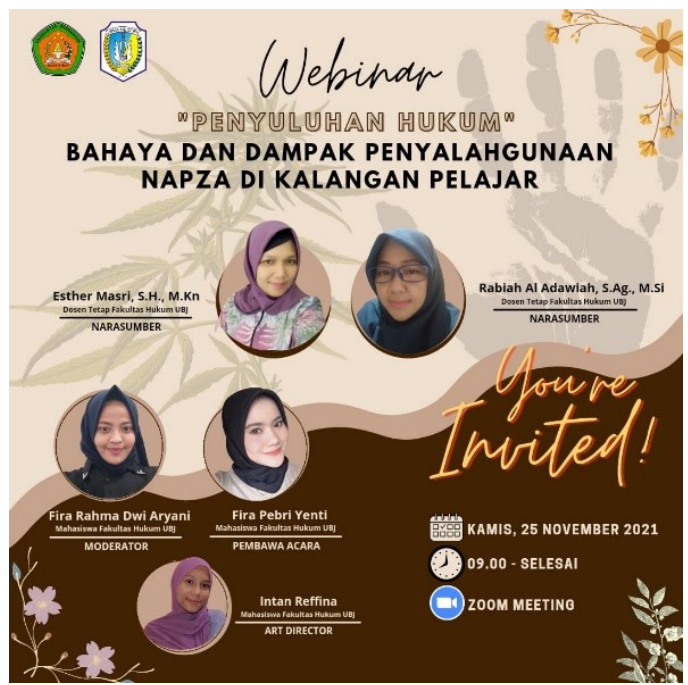

Gambar 1. Sosialisasi Kegiatan Webinar

Dibawah ini adalah gambar (screenshot) penyampaian materi oleh pemateri 1 mengenai bahaya dan dampak penyalahgunaan NAPZA di kalangan pelajar (berisi tentang pengertian, bahaya, dampak serta pencegahan penyalahgunaan Napza).

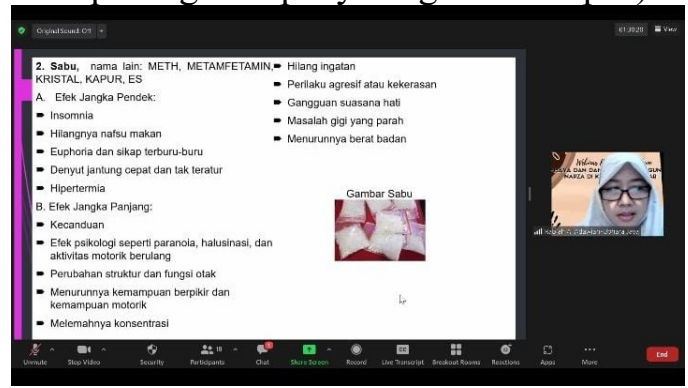

Gambar 2. Pemaparan Materi Bahaya dan Dampak Penyalahgunaan Napza

Penyampaian materi oleh pemateri 2 mengenai aspek hukum penyalahgunaan NAPZA ditunjukkan oleh gambar berikut:

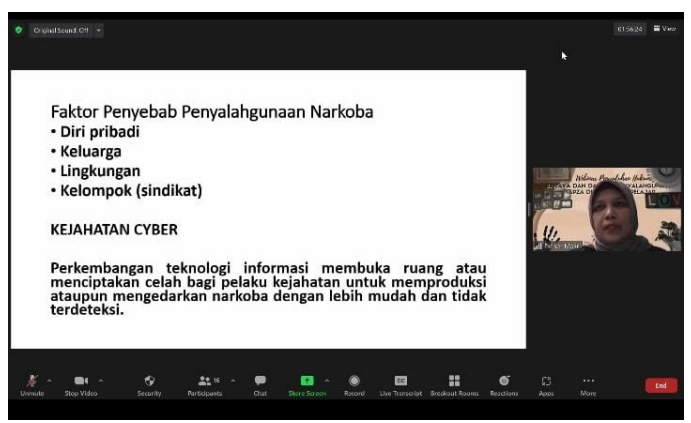

Gambar 3. Pemaparan Materi Tindak Pidana Narkotika

Adapun dokumentasi peserta melalui aplikasi zoom mendengarkan presentasi yang disampaikan oleh pemateri 1 dan pemateri 2 sebagai berikut:

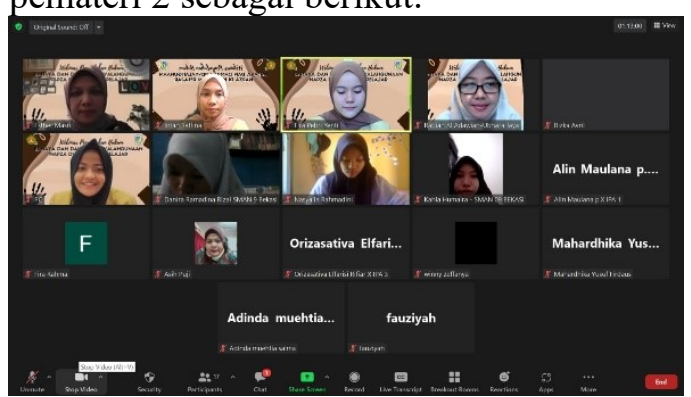

Gambar 4. Peserta yang mengikuti kegiatan Webinar

Tabel 1. Sebelum dan Sesudah Kegiatan Pengabdian Masyarakat di SMAN 9 Bekasi

\begin{tabular}{llll}
\hline No. & Unsur & Pra Pengabdian & $\begin{array}{l}\text { Pasca } \\
\text { Pengabdian }\end{array}$ \\
\hline 1. & Pihak & Mengetahui & Sudah \\
& Pelajar & $\begin{array}{l}\text { sedikit bahaya, } \\
\text { dampak dan cara } \\
\end{array}$ & $\begin{array}{l}\text { memahami } \\
\text { bahaya, dampak } \\
\text { dan cara } \\
\text { pencegah }\end{array}$ \\
& & Nenyalahgunaan & $\begin{array}{l}\text { mencegah } \\
\text { penyalahgunaan }\end{array}$ \\
& & Napza. \\
\hline 2. & Pelangga & Belum mengerti & Sudah mengerti \\
& ran dan & akibat hukum dari & akibat hukum \\
& Sanksiny & penyalahgunaan & dari \\
& a & Napza dan & penyalahgunaan \\
& & sanksinya yang & Napza dan \\
& & diatur dalam UU & sanksinya yang \\
& & diatur dalam \\
& & UU \\
\hline
\end{tabular}

\section{KESIMPULAN}

Penyalahgunaan NAPZA menjadi masalah serius yang dapat membahayakan dan memberikan dampak yang serius di kalangan pelajar. NAPZA membuat pemakainya kecanduan dan ketergantungan, 
semakin lama mengonsumsinya, maka akan semakin kuat memakai zat tersebut dan dosisnya pun meningkat secara eskalatif. Kegiatan penyuluhan NAPZA/Narkotika menjadi sangat penting bagi semua pihak, baik sekolah maupun orang tua untuk terus memberikan pengarahan yang baik mengenai bahaya dan dampak penyalahgunaan NAPZA/Narkotika bagi masa depan pelajar.

Dengan adanya kegiatan pengabdian kepada masyarakat dalam bentuk sosialisasi hukum terkait NAPZA di Sekolah Menengah Atas Negeri 9 Bekasi mampu memberikan pemahaman dan kesadaran bagi para pelajar agar terhindar dari penyalahgunaan NAPZA, serta mengerti akibat hukum dari penyalahgunaan NAPZA dan sanksinya yang diatur dalam UU.

\section{SARAN}

Berdasarkan hasil Penyuluhan Hukum Bahaya dan Dampak Penyalahgunaan Napza Di Kalangan Pelajar, beberapa saran antara lain :

Pertama, kegiatan penyuluhan hukum terhadap siswa/i harus terus digalakkan agar mereka mengetahui dan paham tentang pengertian, jenis, bahaya, dampak, pencegahan serta aspek hukum terkait penyalahgunaan Napza, sehingga para pelajar bisa lebih bijaksana dan berhati-hati agar tidak terjerumus dalam penyalahgunaan Napza.

Kedua, membangun sinergitas antara para guru dan para siswa/i SMAN 9 Bekasi untuk mencegah terjadinya penyalahgunaan Napza.

\section{REFERENSI}

[1] Natalia, S \& Humaedi, S, 2020, Bahaya Peredaran Napza Pada Masa Pandemi Covid-19 Di Indonesia, Prosiding Penelitian dan Pengabdian Kepada Masyarakat, Vol.7, No.2, pp. 387 - 392. https://jurnal.unpad.ac.id/prosiding/article/v iew/28868.

[2] Nur'artavia, M. R., 2017, Karakteristik Pelajar Penyalahguna Napza Dan Jenis Napza Yang Digunakan Di Kota Surabaya, The Indonesian Journal of Public Health, Vol.12, No.1, pp. 27-38. https://ejournal.unair.ac.id/IJPH/article/view/7110.
[3] Soedjono, 1997, Patologi Sosial, Alumni Bandung, Bandung.

[4] Badan Narkotika Nasional, 2019, Pengertian Narkoba Dan Bahaya Narkoba Bagi Kesehatan, https://bnn.go.id/pengertian-narkobadan-bahaya-narkoba-bagi- kesehatan/. Diakses 2 Oktober 2021.

[5] Undang-Undang No 35 Tahun 2009 tentang Narkotika.

[6] Pane, M. D. C., 2021, Ini Fakta Psikotropika dalam Dunia Medis, https://www.alodokter.com/ini- faktapsikotropika-dalam-dunia-medis, diakses 2 Oktober 2021.

[7] Ummu, A., 2008, Apa Itu Narkotika dan Napza, PT Bengawan Ilmu, Semarang.

[8] Martono, L. H., Joewana, S., 2006, Pencegahan Dan Penanggulanaan Penyalahgunaan Narkoba, Cet.I, Balai Pustaka, Jakarta.

[9] Republika.co.id, 2021, Wapres: 180 dari 10 Ribu Penduduk 15-64 Tahun Pakai Narkoba, senin 28 Juni 2021. https://republika.co.id/berita/nasional/u mum/qve48q428/wapres-180-dari- 10ribu-penduduk-1564-tahun-pakainarkoba.

[10] Beritasatu.com, 2021, 27\% Pengguna Narkoba dari Kalangan Pelajar dan Mahasiswa, https://www.beritasatu.com/nasional/7 92291/27-pengguna-narkoba-darikalangan-pelajar-dan-mahasiswa. Diakses 2 Oktober 2021.

[11] Willis, S. S., 2014, Remaja Dan Masalahnya: Mengupas Berbagai Bentuk Kenakalan Remaja Narkoba, Free Sex Dan Pemecahannya, Cet. 5, Alfabeta, Bandung.

[12] Badan Narkotika Nasional, 2020, Bahaya Dan Dampak Negatif Narkoba Bagi

Kehidupan,"https://bandungbaratkab.b nn.go.id/bahaya-dan-dampak-negatifnarkoba-bagi kehidupan/. Diakses 2 Oktober 2021.

[13] Irwansyah, 2006, Pendidikan Jasmani, Olahraga Dan Kesehatan, Garfindo Media Pratama, Bandung.

[14] Assiediqie, A. H., 2019, Pengaruh, Dampak Dan Komplikasi Penyalahgunaan Napza, https://rsupsoeradji.id/pengaruhdampak-dan-komplikasi- 
penyalahgunaan-napza/. Diakses 2 Oktober 2021.

[15] Marpaung, D. S. H., 2019, Bahaya Narkoba Serta Perlindungan Hukum Terhadap Anak Sebagai Pelaku Penyalahguna Narkoba Di Kabupaten Purwakarta, Jurnal Hukum POSITUM, Vol.4, No.1, pp. 98-115. https://journal.unsika.ac.id/index.php/p ositum/article/view/3010.

[16] Firdaus, A. M., Hidayati, E., 2018, Pengetahuan Dan Sikap Remaja Terhadap Penggunaan Napza Di Sekolah Menengah Atas Di Kota Semarang, Jurnal Keperawatan, Vol. 6, No.1, $\mathrm{pp}$. $1-$ 7.https://jurnal.unimus.ac.id/index.php/ $\mathrm{JKJ} /$ article/view/4415/0.

[17] Swari, R. C., 2021, 4 Jenis Narkotika Populer di Indonesia dan Bahayanya Bagi Tubuh, https://hellosehat.com/obatsuplemen/narkoba-terpopuler-diindonesia-apa-efeknya-pada-tubuh/. Diakses 2 Oktober 2021. 